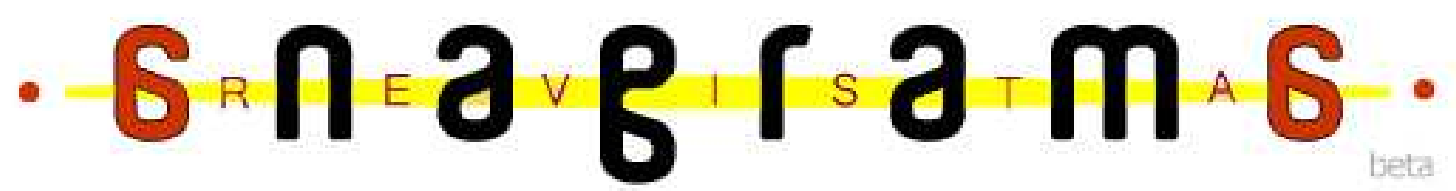

\section{Ou /sto ou Aquilo: uma breve análise da literatura infantil de Cecília Meireles}

\section{Camila U. Ramos da Silua ${ }^{7}$}

\section{Resumo}

Cecília Meireles é uma autora muito consagrada no cenário literário brasileiro, sua obra destinada ao publico adulto é alvo de muitas leituras e análises. Entretanto o que poucos sabem é que a autora também se dedicou à literatura infantil e, mais que isso, foi uma grande educadora, extremamente ativa nas discussões sobre educação. Este trabalho pretende recuperar esse lado da autora pouco estudo, bem como analisar os poemas de $O u$ isto ou aquilo.

Palauras-chaue: Literatura Infantil; Educação; Cecília Meireles.

\section{Cecília Meireles e sua importância na Literatura Infantil}

Conhecida como uma das maiores poetiza do país, Cecília Meireles pôde encantar a muitos com sua poesia: foi lida, relida, ensaiada, estuda e até musicada. Nascida no Rio de Janeiro, Tijuca, em 1901, fica órfã de pai antes mesmo de nascer, e de mãe um pouco antes de completar seus três anos, fora criada pela avó.

Cecília formou-se no Curso Normal do Instituto de Educação do Rio de Janeiro e em 1917, com apenas 16 anos passa a lecionar no magistério primário, torna-se professora universitária em 1935. Além disso, viaja o mundo lecionando, participando de palestras e conferencias sobre Educação e Literatura. Colaborou com diversas revistas e jornais, sendo que em 1930-1931 manteve no Diário de Noticias uma pagina diária sobre os problemas da educação. Seu primeiro livro de poemas, Espectro, é publicado em 1919.

\footnotetext{
${ }^{1}$ Graduanda do Curso de Letras da Universidade de São Paulo (USP).
} 
Assim envolta à escrita literária e consciente dos problemas da educação, passa a dirigir o Centro Infantil, no antigo pavilhão Mourisco, no bairro de Botafogo e então organiza a primeira biblioteca infantil do Rio de Janeiro em 1934. Para Cecília Meireles as bibliotecas "correspondem a uma necessidade da época, e têm a vantagem não só de permitir a criança uma enorme variedade de leituras, mas de instruírem os adultos acerca de suas preferências" (1979: 111).

Em 1951 publica "Problemas da Literatura Infantil", a partir de três conferências proferidas pela autora reunidas num livro que integrava a "Coleção Pedagógica" da Secretaria de Educação do Estado de Minas Gerais. Disposta a analisar os problemas que envolviam a Literatura Infantil, se questiona se haveria uma literatura propriamente infantil e como se poderia caracterizá-la.

Segundo a autora "tudo é uma Literatura só. A dificuldade está em delimitar o que se considera como especialmente do âmbito infantil" (1979: 19). Ora, existe uma grande diferença entre literatura infantil e "livros para crianças", enquanto poeta, Cecília Meireles se nega a aceitar que livros direcionados ao publico infantil com a única preocupação de ensinar, ou seja, textos "didatizados" a serviço do ensino fossem ${ }^{2}$ considerados literatura, pelo contrario deveriam estar a serviço de uma estética literária de qualidade, mais preocupados em promover apreciação estética do que ensinar.

Nos séculos XVIII, XIX e XX a Literatura Infantil passa por um processo de registro, de redação dos textos mais significativos até então, aqueles preservados pela tradição oral como os ricos jogos populares de palavras, as parlendas, adivinhas, provérbios, assim como a divulgação de contos de Charles Perrault.

Além disso, existiam as obras que a principio não eram para crianças, mas acabaram caindo em seus gostos, como as "Aventuras de Robinson Crusoé”, por exemplo. E o oposto também, obras feitas para crianças que se expandiram para o publico adulto como as Fabulas de La Fontaine. Essas inversões nos leva a pensar, assim como levou à Cecília Meireles, que Literatura Infantil "em lugar de ser o que se escreve para crianças, seria a que as crianças lêem com agrado" (1979: 77).

Entretanto a possibilidade de escrever especificamente para crianças não estava descartada, surgem as obras pautadas em três aspectos: o moral, o instrutivo e o recreativo. Mas poucos são os autores que se dedicaram a escrever só para crianças e obtiveram 
sucesso, a maioria escreve também para o publico adulto, como é o caso da poetisa aqui estudada.

Após esse panorama histórico e evolutivo da Literatura Infantil e dessa analise acerca da matéria dos livros infantis, Meireles não apresenta nenhuma "receita" capaz de tornar as obras próprias para os pequenos e iniciantes leitores. Em suma, para a autora, tal literatura deve ser capaz de estimular a imaginação das crianças, e deve estar repleta de lirismo, ou seja, o texto deve atingir-lhes a emoção, torná-los apaixonados pela leitura.

Se analisar os livros é importante, na mesma medida o é estudar o leitor. Tarefa difícil já que cada um recebe a obra de maneira diferente e particular, mas o que mais tem agradado os jovens leitores são os heróis e suas ações. Apesar disso, a autora aponta para o mundo deflagrado em que vive, onde tais obras poderiam parecer ingênuas ao leitor que desde cedo convive e participa do universo adulto e de toda sua violência real e simbólica.

Essa crise porque passa a Literatura Infantil poderia ser resolvida segundo a autora, por meio de uma "universalização" que levasse as crianças a um certo "humanismo", ou seja, ela propõe que se formule uma base literária comum a todos. Esse princípio encobre o objetivo dos educadores da Escola Nova de formarem um "homem novo" capaz de promover uma transformação social.

Para tanto os textos destinados a elas deveriam ser compostos sobre duas bases, "ciência" e "arte": a ciência, preponderantemente a Pedagogia, que apontaria ao autor as características, especificidades do desenvolvimento infantil, seus interesses; e a arte que conduziria o leitor ao "amor" pela leitura.

Além disso, devem seguir certas regras como não "ser perniciosos, não devem expressar os defeitos da sociedade, devem evitar situações fantásticas como punhais para punir traições, situações que levem ao fanatismo, temas que proponham a malícia sexual" (Corrêa, 2001), mesclando as cenas cotidianas com as tradições do passado. Do ponto de vista da linguagem, deveriam ser acessíveis, de simples compreensão.

As reflexões de Cecília Meireles sobre Educação e Literatura Infantil foram feitas na metade do século passado, é claro que diversas transformações nesses campos de interesses aconteceram. Entre avanços e retrocessos as questões levantadas pela autora matem-se ainda viva e pertinente, senão como reflexo da atual situação sócio-educativa e literária, ao menos por focar na necessidade de uma atitude reflexiva e analítica da produção feita para as crianças. 


\section{"Ou isto ou Aquilo"}

A obra poética Ou isto ou aquilo foi publicada pela primeira vez em 1964, 45 anos depois da primeira publicação de Cecília Meireles para adultos. É composta por 56 poemas que na sua grande maioria aliam conhecimento e entretenimento, revelando a preocupação da autora com o inicio do letramento das crianças juntamente com o desenvolvimento de uma apreciação estética; os poemas tendem a incitar a imaginação e a sensibilidade dos pequenos leitores.

Segundo Nelly Novaes Coelho a poesia "é uma linguagem verbal artística, rítmica ou melódica liberta da lógica da linguagem comum" (1980: 42). Dessa forma, a poetisa alia elemento de natureza sonora e musical à subjetividade, mas sem deixar de lado a preocupação educacional.

Em "O mosquito escreve" Cecília retira a matéria da vida cotidiana da criança, já que uma das primeiras atividades escolares é o letramento, mas não é uma criança que escreve, é um mosquito, adentramos, portanto no mundo fantástico, e nos servimos da imaginação para acompanhar esse personagem.

O poema dialoga com a criança não só por fazer uma ponte com sua vida cotidiana, mas também porque interage com ela diretamente, ao indagá-la no penúltimo verso "não é, criança?", o texto verbal e a criança tornam-se um só, a poetisa consegue com muita sutileza transportar a criança para dentro do texto. E assim, ao passo que amplia o imaginário da criança, não deixa de se preocupar com a sua aprendizagem inserindo a alfabetização do mosquito.

Se por um lado o poema visa provocar a imaginação do leitor, a ilustração de Eleonora Affonso não passa de um retrato fiel do personagem desse poema, a ilustração e os dois primeiros versos representam a mesma imagem, pode-se notar que as "pernas" do pernilongo da ilustração estão trançadas assim como no texto verbal, além disso, para se traçar um "M" são necessários quatro traços, de forma que como na ilustração, se repararmos bem nas pernas do pernilongo, poderemos imaginar a letra "M" um pouco destorcida. 


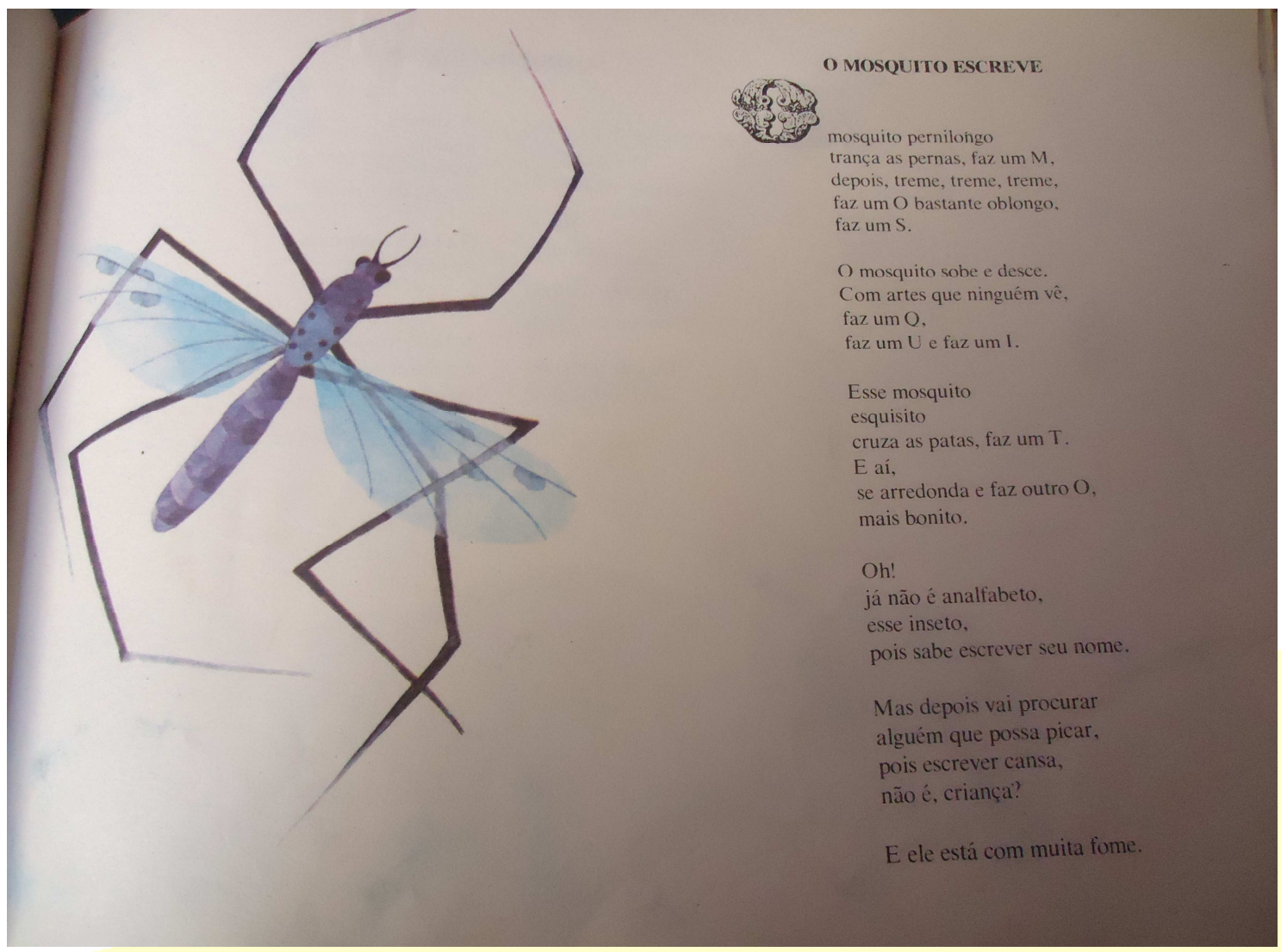

As imagens sonoras são abundantes nos poemas dessa obra, os jogos de palavras transformam o mundo das letras em um mundo onírico, fazendo com que o leitor experiência uma fantasia envolvente e de extrema beleza. Assim, aos olhos dos adultos "Carolina" colore o mundo ao seu redor com uma serie de aliterações de "rr" e se utilizando das letras de seu nome para compor outras palavras, mas aos olhos de uma criança, ou ainda aos olhos poéticos, "Carolina", seu colar e a colina participam de uma brincadeira capaz de divertir ate mesmo o "Sol".

Da mesma maneira "Raul" vira "luar", e tantos outros exemplos. Essas brincadeiras nos revelam a "intencionalidade pedagógica de Cecília em 'Ou isto ou aquilo', sugere que a poeta propõe um jogo dinâmico no fazer psicolingüístico da criança, que contribua para um fazer ativo em suas competências afetivas e emocionais, mas, também, que facilite a sua acepção e aprendizagem da língua escrita por meio da codificação e decodificação dos signos e da construção de novos significados" (Fernandes, 2006).

Já o poema que dá nome ao livro trás claramente a temática da "escolha". A utilização da forma "ou... ou" nos remete a questão de impossibilidade de dominar ou 
possuir o todo, de forma muito concreta, apesar de sensível esse poema revela a criança uma das maiores máximas da vida, mostra que toda escolha gera uma renuncia.

A perda de seus pais fez com que Cecília desde muito cedo aprendesse lidar com a falta, com a ausência e com a solidão, num segundo plano de leitura é justamente isso que encontramos nesse poema, pois, por exemplo, se o "eu" desse poema optar por colocar luvas, automaticamente estará optando pela ausência do anel.

Ao fim do poema o eu lírico nos revela

\section{“Mas não consegui entender ainda}

Qual é melhor: se é isto ou aquilo."

Ora, a incerteza e a duvida muitas vezes é acompanhada da angustia, já que é necessário se decidir entre "isso ou aquilo". Essa criança não conseguiu entende ainda o que é melhor, e possivelmente nunca entenderá, pois apesar de dirigido a uma criança, esse poema pode muito bem sensibilizar a um adulto, pois as escolhas nunca nos abandonam, pelo contrario, vão ficando mais urgentes, mas sérias e mais difíceis.

A decisão a ser tomada é muito difícil, por isso a ilustração trás todos os elementos do poema, afinal não cabe a ilustradora escolher, nem ao poeta ou ao professor, cabe somente a criança. Assim vemos na imagem abaixo o anel e a luva, o doce e o dinheiro, o sol e a chuva e não um ou outro. E no meio de todas essas possibilidades está a criança, que ao invés de feliz por conjugar todos seus desejos, aparenta tristeza e angustia por saber que cedo ou tarde terá de escolher. 


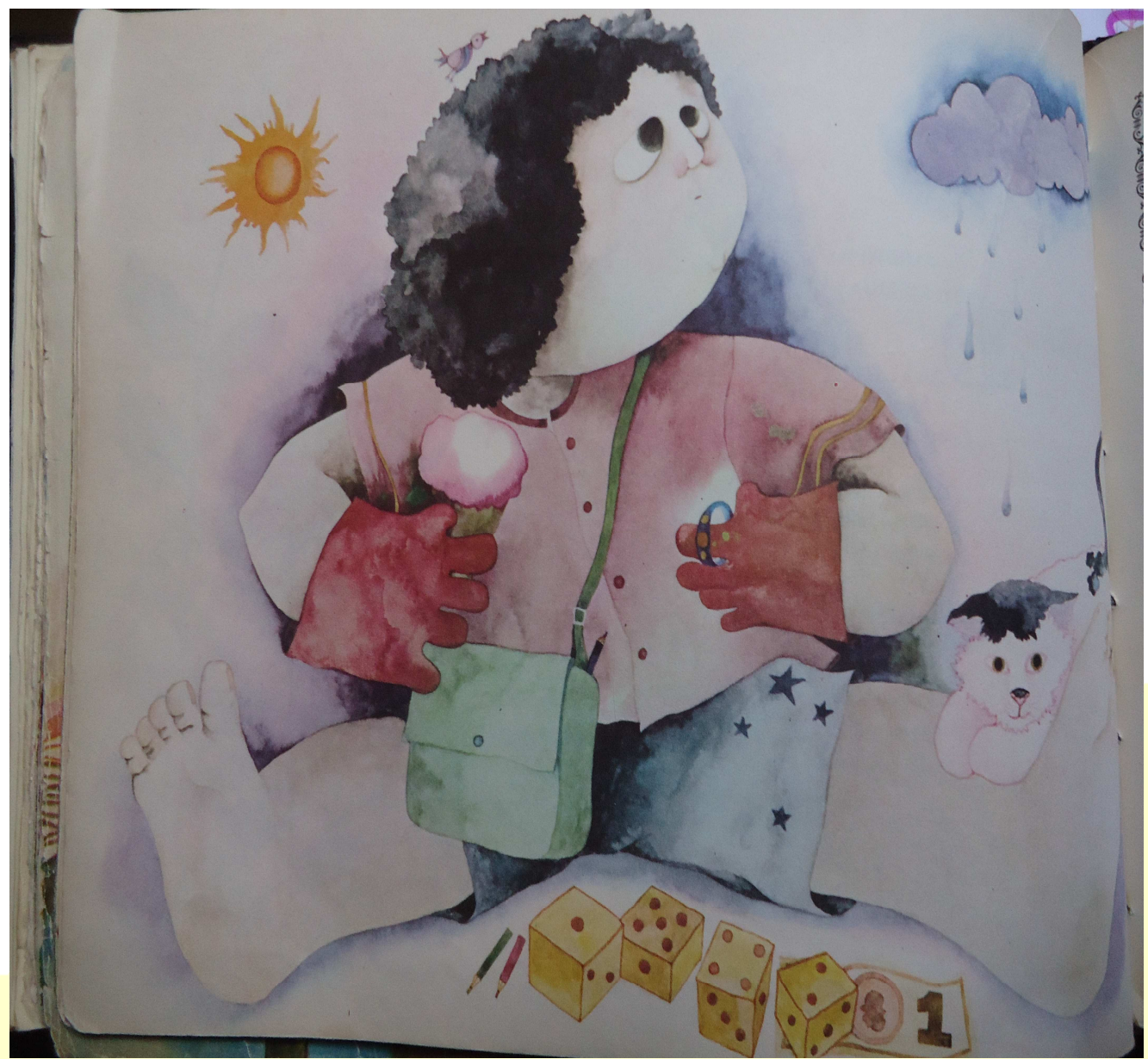

Se no poema "Ou isto ou aquilo" estamos diante de uma impossibilidade de escolha, no poema "Uma palmada bem dada" não é nada muito diferente que encontramos. A menina que é retratada como manhosa também se sente impossibilitada de algumas coisas, aqui não porque terá que fazer renúncias, mas sim porque descobre a imperfeição das coisas. O banho quente causa calor, o banho frio, arrepio; o banho morno seria uma solução, mas a criança ainda não possui equilíbrio, suas emoções são intensas e todos os seus sentimentos potencializados.

Nas escolhas do poema anterior, as perdas estavam ligadas a ganhos, aqui não, a criança esta diante de escolhas necessárias, mas que de nenhuma forma a satisfaz. Por exemplo, se antes ela não escolhia porque se sentia confusa, aqui ela não quer porque não se sente satisfeita. Há sempre um motivo para não querer fazer as coisas: as unhas cortadas ficarão tortas, dormir lhe deixa com medo. Temos então dois poemas que dialogam, pois possuem o mesmo tema, a impossibilidade, mas com abordagens bem distintas. 


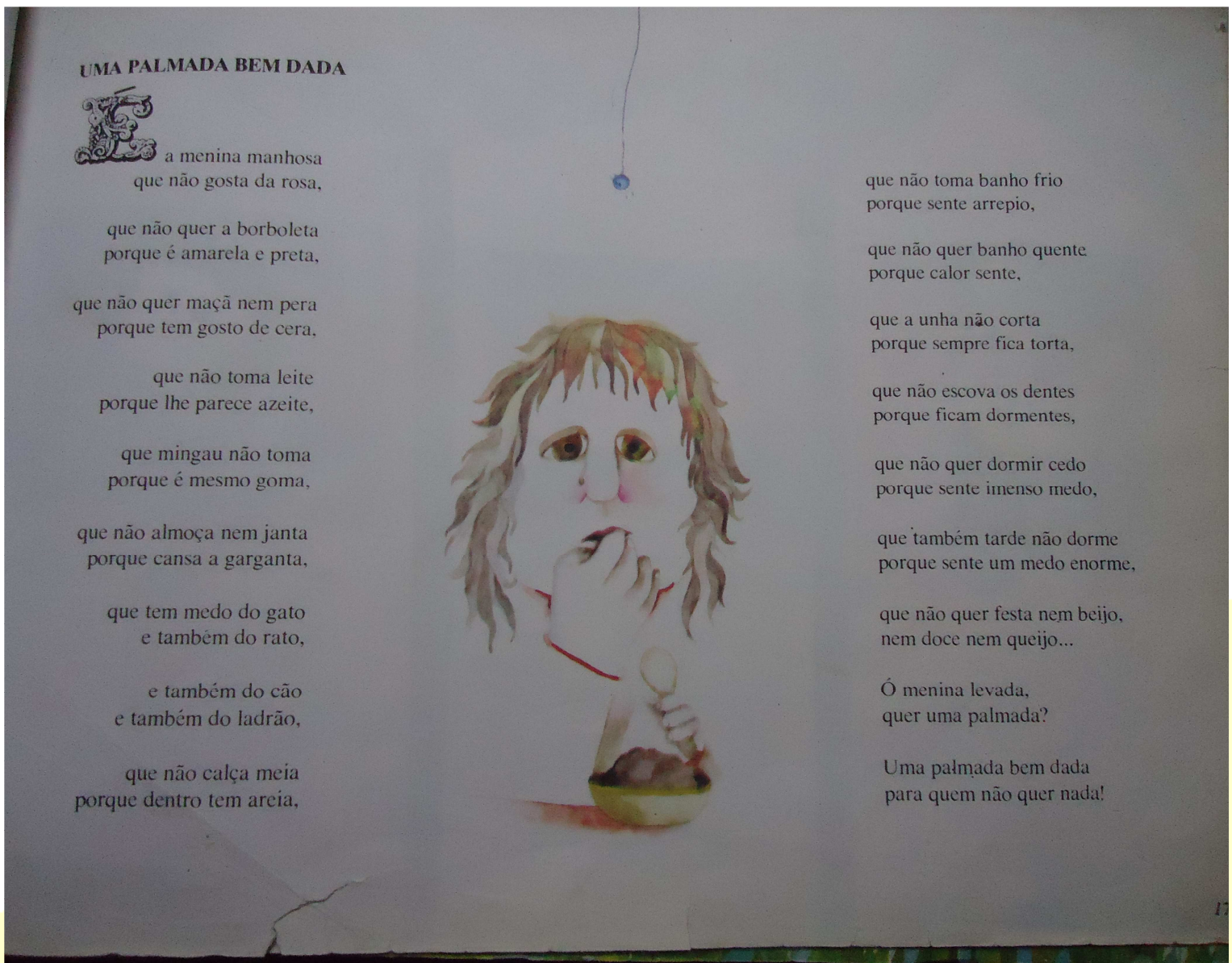

Ao ler seguidamente os 46 poemas, uma imagem fica saliente: a imagem da água; em forma de rio, de chuva, mar, temporal, a água aparece em 16 poemas. Se buscarmos a simbologia da água perceberemos que ela está ligada à vida e para algumas religiões é símbolo de purificação, mas mais que isso "simboliza a infinidade de possibilidades" (Lexikon, 2007:13).

Essa infinidade de possibilidades é sem dúvida o que permeia não só "Ou isto ou aquilo" mas toda a obra, e mais além, toda a vida de Cecília Meireles. Como artista multifacetada, a autora consegue articular sua maestria enquanto poeta, com preocupação pedagógica enquanto educadora, e assim proporciona ao seu jovem leitor uma experiência de imaginação e apreciação estética. 


\section{REFERÊกCIAS BIBLIOGRÁFICAS}

COELHO, Nelly Novaes. Literatura e linguagem. São Paulo, Quíron, 1980.

CORREAA, Luciana B. Vial. Infância, escola e literatura infantil em

Cecília Meireles.Dissertação de Mestrado. Departamento de Educação da PUC-Rio, maio de 2001. Orientadora: $\operatorname{Prof}^{\mathrm{a}} \operatorname{Dr}^{\mathrm{a}}$ Sônia Kramer.

LEXIKON, H. Dicionário de símbolos. $7^{\mathrm{a}}$ edição. São Paulo, Editora Pensamento-Cultrix, 2007

MEIRELES, Cecília. Problemas da literatura infantil. $3^{\text {a }}$ edição. São Paulo, Summus, 1979.

. Ou isto ou aquilo. $2^{\mathrm{a}}$ Edição. Rio de Janeiro, Editora Civilização Brasileira, 1977. 